\title{
Exploring the Laboratory Construction in Finance and Economics Colleges and Universities by Adopting Virtual Simulation Technology
}

\author{
Song Ren ${ }^{1}$, Cao $\mathrm{Yu}^{2}, \mathrm{Xu}_{\text {ZhiChao }}{ }^{*}$, LI Yang ${ }^{4}$, Liang BiMing ${ }^{5}$ \\ ${ }^{1}$ Jilin University of Finance and Economics, Changchun 130119 \\ ${ }^{2}$ Harbin Finance University, Harbin 150000 \\ ${ }^{3}$ Jilin University of Finance and Economics, Changchun 130119 \\ ${ }^{4}$ Jilin University of Finance and Economics, Changchun 130119 \\ ${ }^{5}$ Jilin University of Finance and Economics, Changchun 130119
}

\begin{abstract}
In finance and economics colleges and universities, for various reasons, it is difficult for students to access the core knowledge of the major practical course. As a result, practical course is just a formality, nothing but eye candy. Therefore, constructing the laboratory by adopting virtual simulation technology can achieve the real purpose of practical course. Virtual simulation technology is mainly used to simulates realistic equipment. It uses network technology, multimedia technology and 3D technology to make the high definition simulation effect. The demonstration of these three-dimensional simulations allows students to have comfortable experience. Therefore, finance and economics colleges and universities adopt virtual simulation technology to simulate realistic high-value equipment, allow students to give full play to their imagination in this virtual simulation environment, and take full advantage of what they have learned to achieve the students' real purpose in university.
\end{abstract}

Keywords-Virtual simulation technology; Practical course; Virtual simulation laboratory; Cultivation of innovative talents; Transformation of education; Computer technology

\section{INTRODUCTION}

The significance of virtual simulation technology in the construction of financial colleges and universities

With the advancement of science and technology, the development of economy and society, computer technology, network technology, and virtual simulation technology are rapidly rising. The existence of this virtual simulation technology is concerned by various fields of society. With the gradual maturity of virtual simulation technology, people have begun to realize the application value of virtual simulation technology.
Trying to stand in the perspective of finance and economics colleges and universities, through an intensive study of virtual simulation technology and applied to the laboratory construction, it not only makes the practical courses in colleges and universities more vivid and comprehensive, but also make the students more active and prospective. Stimulate students creative consciousness and creative inspiration, improves the team spirit and comprehensive quality of students, cultivating students' practical ability and self-study ability. Therefore, the construction of the virtual simulation technology in universities of finance and economics laboratory, it has improved the teaching quality in colleges and universities, promoted the transformation of education in colleges and universities. And played an important exemplary role in terms of practice teaching and cultivation of innovative talents.

Constructing the virtual simulation laboratory in universities of finance and economics, the main aim is to get students through the practice teaching course to have access to a wider range of other more specialized core knowledge and expertise, and all knowledge applied to practical work. In finance and economics colleges and universities, majoring in accounting, finance, taxation, business, management, etc. Students of these specialties standing on the internship positions are hard to get access to the real core of professional knowledge, it causes students don't know what to learn before entering the society, no professional knowledge will be applied after entering the society, the application of knowledge and society seriously out of line, it is a kind of pressure for the development of society, also for students who have just entered the community. To resolve this contradiction of the society and universities, the construction of laboratory based on virtual simulation technology, the reform of practical teaching mode can be achieved, the development of education has been promoted, meet the requirements of china's economic development, on the social economy development has the vital significance. 
II. THE PRESENT SITUATION OF THE CONSTRUCTION OF LABORATORY OF VIRTUAL SIMULATION TECHNIQUE AT HOME AND ABROAD

\section{A. The present situation of the construction of virtual simulation laboratory in China}

In china, the virtual simulation technology and its application in terms of starting slightly later compared with foreign countries, but they have achieved many successes. At present, all areas of society are studying virtual simulation techniques and have corresponding applications. The use of virtual simulation technology to build laboratories in financial and economic colleges and universities is not only a key task of university information construction, but also an indispensable part of practical teaching in universities.

Among the universities, The "Physical Virtual Simulation Experimental Teaching Center" established by University of Science and Technology of China, is the first state-level virtual simulation experimental teaching center in physics, It is also one of the first 100 list national virtual simulation experimental teaching centers selected by the Ministry of Education. Jilin University established the virtual simulation of threedimensional exploration of experiment teaching center of geological resources, jointly organized by 5 Jilin University branches, they are: the branch of earth exploration science and technology, the branch of earth sciences, the branch of construction engineering, the branch of environment and resources, the branch of Instrument science and electrical engineering.

This kind of virtual simulation experiment course can cultivate students' scientific accomplishment, encourage students' creativity, can also train students to apply what they have learned to solve research problems and practical problems, it has played an important role in the cultivation of talent in universities in china.

\section{B. The present situation of the construction of foreign virtual simulation laboratory}

The concept of Virtual Laboratory (VR), first proposed by Professor William Wolf of the University of Virginia in the United States in 1989, the original purpose was to provide a unified working platform for scientific researchers in different regions, facilitate the remote collaboration or sharing of data between researchers in different laboratories [1].

The generation of Virtual Laboratory is inseparable from the Virtual Reality (VR) technology. Virtual reality technology appeared in the 1960s, it is people who simulate virtual space through computers, simulate the user's senses of sight, hearing, and touch, and combined with reality, generate a realistic 3D virtual environment, and users are immersed in technology that enables users to interact directly with the environment [2]. In May 1995, United Nations Educational Scientific and Culture Organization (UNESCO) defined virtual laboratories as: in order to achieve remote collaboration, experimental research and other innovative activities, electronic studios that generate and publish results through decentralized information and communication technology [3].
In the United States in the 1990s, the research of virtual laboratories was included in the strategic planning of its research and development. Web Lad virtual laboratory of the Massachusetts Institute of Technology, an online testing facility, it was put into use in 1998. The University of Michigan's Virtual Chemistry Laboratory has realized a virtual experiment of catalyst passivation and non-isothermal reaction [4]. The cyber-control engineering virtual laboratory at Ruhr University in Germany presented the experimenter with a three-dimensional experimental scenario, it relies on the simulation features of each virtual device to realize the virtual interactive operation of the control engineering experimental project. Other well-known examples include the "Live hem" experimental project in the Department of Chemistry at the University of Oxford, UK, National University of Singapore Virtual Electronic Laboratory, University of Pavado, Italy, remote virtual education laboratory, etc. [5].

\section{THE MAIN CONTENTS OF THE CONSTRUCTION OF} LABORATORIES IN FINANCIAL INSTITUTIONS BY USING VIRTUAL SIMULATION TECHNOLOGY

In the financial colleges and universities, the real purpose of practical teaching is to cultivate students' practical ability and innovation ability, ultimately, students can be promoted to society and develop steadily in society. In the teaching system of higher education, practical teaching has an irreplaceable role in theoretical teaching. First of all, through the study of the experimental class, students can deeply understand the theoretical knowledge they have learned in the classroom, and pass through the analogy to deepen the expansion of knowledge, second, through the study of experimental classes, students can inspire students' interest in learning, develop students' learning ideas, and cultivate students' analytical and solving abilities, finally, students can exercise their scientific research skills through the study of experimental classes, through the observation of various experimental phenomena, the analysis and judgment of the problems, so as to improve their ability to summarize, cultivate students' sense of innovation and good thinking habits. Compared with theoretical teaching, experimental teaching is characterized by its practicality, creativity, and intuitiveness, it plays an important role in training students to learn knowledge, improve their practical ability, and master scientific research methods [6].

In the virtual simulation laboratory, build a virtual economic market environment platform, the platform is driven mainly by the manufacturing industry, driven by the trade and economic competition, and driven by the assistance of the service industry to form a virtual simulation of the integrated economic market system. In this platform, industrialization, informatization, and industrialization are combined to form a wide range, three-dimensional environment. This virtual economic market environment platform integrates the practical operations of financial professionals, accounting professionals, business professionals, management professionals, and tax professionals, with enterprise manufacturing and business operations as the core business lines, it extends to other service companies to form a demand supply chain. 
In this virtual simulation lab, you need a real identity login system, unified authentication, the process of internship is made into a three-dimensional structure of navigation, making it easy for students to learn and understand at a glance. The course of the entire practical teaching course is given in the form of a course announcement, put the rules in the platform into the knowledge base, so that students can self-study and understand how to operate the platform.
If students only want to learn a certain professional knowledge, in this lab, you can take this module out for learning simulation, improve the level of difficulty of this module, lead to students understand how this professional expertise is applied to practical work. Finally achieve the goal of applying what you have learned.

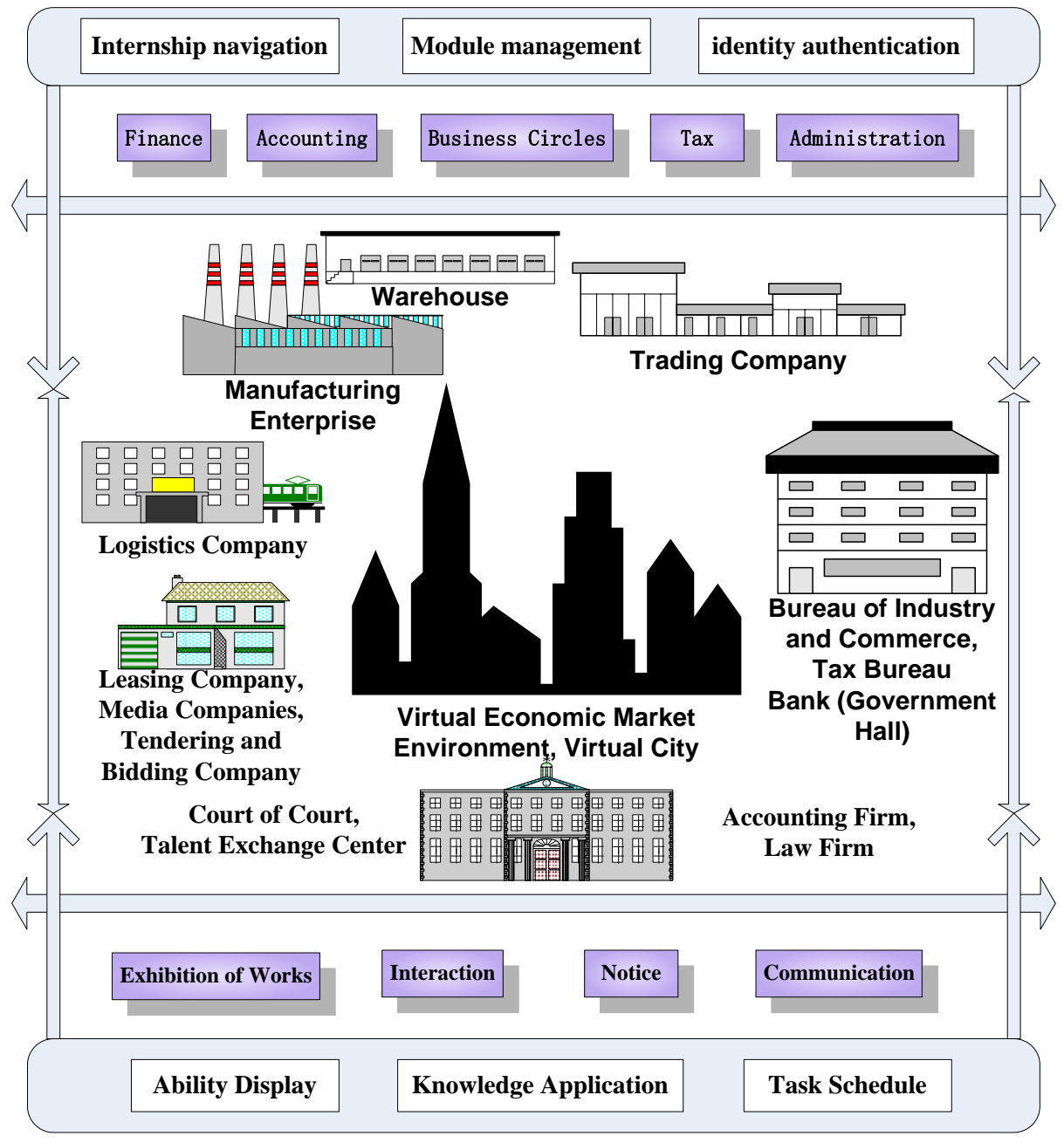

Fig. 1. As shown in the lab module structure

\section{THE PROSPECTS OF CONSTRUCTING LABORATORIES IN FINANCIAL AND ECONOMIC INSTITUTIONS BY USING VIRTUAL SIMULATION TECHNOLOGY}

For any university, theoretical teaching and practical teaching are important, apply theory to practice and verify theory with practice. Theory allows students to deepen their understanding, practice can cultivate students' sense of innovation. Therefore, training students' practical ability is a very important teaching process.

In finance and economics universities, through the development of virtual simulation technology, integrate the application of multimedia technology network technology, and apply its technology to the construction of laboratories, it is the reform of the teaching system in colleges and universities. It is a teaching process that traditional practice teaching cannot achieve.

University of finance and economics construction virtual simulation laboratory, from the teaching point of view, using virtual simulation technology, students do not have to really handle high-risk steps, from a research perspective, compared with traditional technologies, virtual simulation technology can provide researchers with a richer experimental environment, to achieve the purpose of imparting professional skills using modern educational technology [7].

With the advent of the information age, with the development of computer network technology, the technology of building a virtual simulation laboratory will be constantly 
improved and developed, the advantages of using virtual simulation technology in teaching are obvious. The application of virtual simulation technology construction laboratory in colleges and universities is also an inevitable trend in the development of laboratory construction, the virtual simulation technology construction laboratory in colleges and universities will play a more and more important role in practical teaching.

Therefore, practical teaching cannot be realized without the application of virtual simulation technology. The construction of virtual simulation laboratories is valued by many universities, it has become a research hotspot in laboratory construction.

\section{ACKNOWLEDGMENT}

Foundation item: Supported by The "13th Five-Year" science and technology project of the Jilin Provincial Education Department "the exploration and Research on the construction of a cross professional integrated simulation training platform for finance and Economics Colleges and universities" (contract number: JJKH20170122KJ).

Foundation item: Supported by Jilin Provincial Department of education, humanities and social sciences research, 12th
Five-Year plan topic "value management driven sustainable development of Jilin's leading agricultural enterprises" (contract number: 2016465).

\section{REFERENCES}

[1] Goldberg, H. What is virtual instrument [J].IEEE Instrumentation \& Measurement Magazine, 2000, 3(4):10-13.

[2] Chen Changkai. Application and Research of Virtual Experimenta Teaching System [J]. Modern Business Industry, 2013, 13:136-137.

[3] James, R V. Report of the Expet Meeting on Virtual Laboratories [M]. United Nations Educational, Scientific and Cultural Organization. Paris: UNESCO.2000:3-5

[4] Zi Jihong. Overview of Virtual Laboratory Research[J]. Life Science Instruments, 2014(Z1):34-37.

[5] Ma Shihai. Research on the Construction of Network Virtual Laboratory[J]. China Electric Power Education, 2013(1):164-165.

[6] Wu Xinhua, Wan Qiang. The Application of Virtual Experiment in College Teaching [J]. Journal of Pingxiang University, 2013, 30(6):9194.

[7] Zhao Shibin. Research and Implementation of Virtual Reality Technology in University Teaching [J]. Audio-Visual Education Research, 2001(2):30-35. 